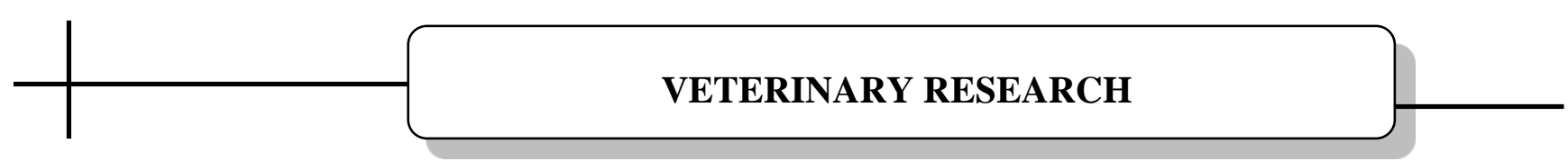

UDC 619: 636.7: 616.4-07 / .08: 612.398.12

DOI: 10.15587/2519-8025.2021.241207

\title{
INFORMATIVITY OF LIPID METABOLISM INDICATORS FOR DIAGNOSTICS AND ESTIMATION OF THE EFFECTIVENESS OF TREATMENT OF DOGS WITH PANCREATITIS
}

\author{
Andrii Zemlianskyi, Olga Tymoshenko, Roman Dotsenko, Yevheniia Vashchyk, \\ Andrii Zakhariev, Nataliia Seliukova
}

\begin{abstract}
The aim of the research: to substantiate the pathogenetic role of lipid metabolism disorders in the occurrence and course of pancreatitis in dogs and to establish the informativeness of its indicators for diagnosis and evaluation of treatment effectiveness based on clinical and laboratory research methods.

Materials and methods. Used clinical, instrumental, laboratory methods, including morphological studies of blood, urine, biochemical studies of serum: determination of the lipid profile by the content of triacylglycerols, total cholesterol, lipoproteins cholesterol of very low - HDL, low - LDL and high density - VLDL, traditional tests and statistical methods.

Results. It was found that the most significant changes are inherent in the metabolism of lipids and lipoproteins in the serum: significantly increased concentrations of cholesterol, triacylglycerols, LDL cholesterol and especially LDL cholesterol. The content of HDL cholesterol, on the contrary, in the acute course of pancreatitis is below normal. The content of triacylglycerols, LDL cholesterol and VLDL remains high. Total cholesterol is normalized, and the level of HDL is below normal.
\end{abstract}

Conclusions. Serum lipidogram of dogs without clinical symptoms of pathology does not differ in composition from the results obtained by other researchers. For pancreatitis in dogs, the concentration of total cholesterol increases by 1.9 times, triacylglycerols - by 5.4 times, cholesterol VLDL - in 6.0 times and LDL cholesterol - 7.7 times. The content of HDL cholesterol, in contrast, in the acute course of pancreatitis is 1.5 times lower than in clinically healthy dogs. Treatment reduces the degree of hyperenzymemia by ALT and AST, but $\alpha$-amylase activity is not normalized in dogs. Above normal levels of triacylglycerols, LDL cholesterol and VLDL, and HDL cholesterol remain low, despite treatment

Keywords: lipid metabolism, pathogenesis, diagnostics, lipidogram, biochemical indexes, biochemical parameters, dogs, pancreatitis

How to cite:

Zemlianskyi, A., Tymoshenko, O., Dotsenko, R., Vashchyk, Y., Zakhariev, A., Seliukova, N. (2021). Informativity of lipid metabolism indicators for diagnostics and estimation of the effectiveness of treatment of dogs with pancreatitis. ScienceRise: Biological Science, 3 (28), 26-32. doi: http://doi.org/10.15587/2519-8025.2021.241207

(C) The Author(s) 2021

This is an open access article under the Creative Commons CC BY license hydrate

\section{Introduction}

In domestic sources there are few publications on the violation of lipid metabolism in small domestic animals, in particular in dogs [1,2]. This issue is of particular interest not only as a problem of veterinary medicine, but also in the general biological sense, because these animals in many cases are models of hu- man pathology [3]. Many issues regarding lipid metabolism disorders in dogs are debatable. It is also known that dogs are characterized by a high content of alpha-lipoprotein fraction (HDL), as a result of which they very rarely develop vascular atherosclerosis [4]. To date, there are no in-depth studies of the role of lipid metabolism disorders in the occurrence of pathol- 
ogy of the internal organs of dogs, in particular pancreatitis $[5,6]$.

Pancreatitis is one of the most pressing problems of gastroenterology [1]. According to modern hepatologists, "pancreatitis is a mysterious process with an unclear pathogenesis, unpredictable clinical picture and unclear course". In the conventional sense of the term, it is not inflammation: it is a disease that occurs under the influence of a number of factors that leads to activation of enzymes of the parenchyma of the pancreas and its ducts, followed by digestion of glandular tissue [7, 8]. Hypertriacylglycerolemia, which occurs for various reasons, is currently a recognized risk factor for pancreatitis. Etiological factors, in addition to disorders of lipid metabolism, can also be emboli, ischemia of pancreatic tissues and others [6].

If in human medicine the problems of pancreatitis are taken care of by doctors of many specialties - gastroenterologists, hepatologists, abdominal surgeons, resuscitators and others [9-11], then in veterinary medicine this pathology remains a therapeutic problem. Thus, its solution requires a lot of practical skills, which are inextricably linked with the need for in-depth knowledge not only of internal medicine, but also pathological physiology, fundamental and clinical biochemistry, functional diagnostics and pharmacology.

The link between hyperlipidemia and pancreatitis was first noted in the human body in 1865. Today, severe hypertriacylglycerolemia is a recognized risk factor for pancreatitis in humans. The mechanism by which it causes pancreatitis has not been fully elucidated, but it has been suggested that serum triacylglycerols (TG) are hydrolyzed in increased amounts by pancreatic lipase, leading to excess production of volatile fatty acids that are toxic to pancreatic acin cells [12]. In experimentally induced canine pancreatitis, infusion of bile into the duct of the pancreas led to only a slight increase in TG in the pancreas [13]. However, induced secondary hypercholesterolemia caused an increase in LDL cholesterol. These data confirm that hyperlipidemia plays a significant role in the development of pancreatitis. Dogs with spontaneous pancreatitis often have hyperlipidemia. In some cases, it may be involved in its occurrence, instead of being a consequence [14], i.e. hyperlipidemia is a risk factor for pancreatitis. A possible mechanism leading to pancreatitis is the fact that increased amounts of lipids, especially chylomicrons entering the capillaries of the pancreas, will be hydrolyzed by pancreatic lipase. The short-chain fatty acids that are formed could damage the epithelium or acinar cells of the pancreas. Pancreatic lipases, which are released in large quantities, enter the bloodstream and carry out the hydrolysis of triacylglycerols, which leads to even greater formation of fatty acids and more significant damage to the pancreas. This view was confirmed experimentally when a filler containing a high concentration of triacylglycerols or volatile fatty acids was injected into the dog's pancreas, leading to edema and massive hemorrhage of the gland. At the same time a large amount of alpha-amylase entered the bloodstream. Based on this experiment, it is suggested that a significant concentration of chylomicrons and VLDL may interfere with blood microcirculation in the pancreas, which in turn will lead to partial stagnation, accumulation of lipids in the blood, their hydrolysis and damage to gland cells in contact with them [15]. At the same time a large amount of alpha-amylase entered the bloodstream. Based on this experiment, it is suggested that a significant concentration of chylomicrons and VLDL may interfere with blood microcirculation in the pancreas, which in turn will lead to partial stagnation, accumulation of lipids in the blood, their hydrolysis and damage to gland cells in contact with them [15]. At the same time a large amount of alphaamylase entered the bloodstream. Based on this experiment, it is suggested that a significant concentration of chylomicrons and VLDL may interfere with blood microcirculation in the pancreas, which in turn will lead to partial stagnation, accumulation of lipids in the blood, their hydrolysis and damage to gland cells in contact with them [15].

The aim of work was to substantiate the pathogenetic role of lipid metabolism disorders in the occurrence and course of pancreatitis in dogs and to establish the informativeness of its indicators for diagnosis and evaluation of treatment effectiveness based on clinical and laboratory research methods.

\section{Materials and methods}

The work was performed during 2011-2021 on the basis of Luhansk National Agrarian University and veterinary clinics of Luhansk and Kharkiv. To achieve this goal, 125 dogs were examined, from which 15 animals of different breeds and sexes were selected, aged 3-7 years, approximately the same weight, without clinical signs of pathology, from which a control group was formed. We also found 24 individuals with clinical signs of acute pancreatitis or exacerbation of chronic. An experimental group was formed from them. Blood samples were taken from the subcutaneous vein of the forearm.

All experiments in the current animal study are in accordance with the recommendations of ARRIVE and were conducted in accordance with the UK Animal Act (scientific procedures) of 1986 and the relevant guidelines and EU Directive 2010/63/EU on the protection of animals used for scientific purposes. Animal studies were conducted considering the basic principles of bioethics (conclusion approved by the Commission on Bioethical Examination of Luhansk National Agrarian University from 26.01.2014).

Clinical, instrumental (ultrasound) and laboratory methods were used to solve the purpose and tasks, including morphological studies of blood, urine, biochemical studies of blood serum: determination of the lipid profile (lipid profile) by the content of triacylglycerols, total cholesterol, VLDL, LDL and HDL, traditional tests and statistical methods [16].

Determination of total protein was performed by biuret reaction, protein fractions - by turbidimetric method, total cholesterol content - by Ilk method, total and conjugated bilirubin - by Yendrashek method, glucose - by glucose oxidase method, activity of ALTFideni-Asat $\alpha$-amylase - by the Caraway method. In the serum of animals, in addition to these biochemical tests, 
determined lipid profile, which included the content of triacylglycerols, total cholesterol, as well as cholesterol lipoproteins very low (VLDL), low (LDL) and high density (HDL) [17]. Determination of serum lipid metabolism was performed by the following methods: triacylglycerols - using the enzymatic colorimetric method of the test "Triglycerides SR Mono" (Triglycerides SL Mono, set "Biopharma", UKRAINE); high-density lipoprotein (LP) cholesterol (HDL, or $\alpha$-lipoproteins) was determined after precipitation from plasma with heparin (possibly manganese chloride or other precipitants). Low-density lipoprotein (LDL), very low-density lipoprotein (VLDL) cholesterol was calculated from tests combined in a lipid profile that included triacylglycerols, total cholesterol, and $\alpha$-LP cholesterol. To determine the content of LDL cholesterol used the formula: total cholesterol - (HDL cholesterol + VLDL cholesterol). To determine the cholesterol content of VLDL used the formula: Triacylglycerols: $2.18[5,17]$.

All calculations of the obtained data were performed on a personal computer using the statistical program STATISTICA 7.0 (StatSoft, USA) with the determination of arithmetic mean $(\mathrm{M})$, mean error $(\mathrm{m})$, confidence interval $(\mathrm{CI})$, calculated by the formula $\mathrm{CI}=\mathrm{M} \pm \mathrm{tm}$ (for $\mathrm{p}<0.05 ; \mathrm{p}<0.01 ; \mathrm{p}<0.001)$ and Limit indicators $[5,17]$.

\section{Research results}

The serum of animals of the control and experimental groups was determined by the content of TG, total cholesterol, as well as the fractional composition of lipoproteins, the level of total protein, total bilirubin, urea, creatinine, ALT, AST and $\alpha$-amylase activity. Since lipid metabolism is known to suffer from acute pancreatitis, an analysis of the content of lipids and lipoproteins (lipid profile) was performed both before and after treatment of these same animals (Table 1). There was a probable increase in total cholesterol by 1.9 times compared with a group of clinically healthy dogs. The concentration of TG in the acute course of pancreatitis increased 5.4 times. Analysis of the level of individual fractions of the lipid profile shows that patients with pancreatitis reduce the level of HDL cholesterol (by $31.7 \%$ ). However, the most significant changes are inherent in the LDL and VLDL fractions - in pancreatitis there was a significant increase in the average cholesterol level of both fractions (7.7 and 6.0 times, respectively) compared with a group of clinically healthy animals. An increase in total cholesterol of 1.9 and LDL cholesterol in 7.7 times indicates the development of hyperlipidemia, characteristic of pancreatitis, both acute and chronic, and usually due to increased activity of lipoprotein lipase.

Table 1

Indicators of lipid and lipoprotein metabolism in the serum of dogs with pancreatitis (mmol/l)

\begin{tabular}{|c|c|c|c|c|c|c|}
\hline Indicator & Total cholesterol & Triacylglycerols & $\begin{array}{c}\text { HDL } \\
\text { cholesterol }\end{array}$ & LDL cholesterol & $\begin{array}{c}\text { VLDL } \\
\text { cholesterol }\end{array}$ \\
\hline \multicolumn{7}{|c|}{ Clinically healthy animals, $\mathrm{n}=15$} \\
\hline $\mathrm{M} \pm \mathrm{m}$ & $4.71 \pm 0.26$ & $0.74 \pm 0.08$ & $3.79 \pm 0.25$ & $0.58 \pm 0.06$ & $0.30 \pm 0.04$ \\
\hline $\mathrm{Lim}$ & $2.99-6.86$ & $0.21-1.32$ & $2.12-5.98$ & $0.27-1.10$ & $0.1-0.61$ \\
\hline $\mathrm{TI} \mathrm{p}<0,05$ & $4.16-5.26$ & $0.57-0.91$ & $3.26-4.32$ & $0.45-0.71$ & $0.21-0.39$ \\
\hline $\mathrm{TI} \mathrm{p}<0,01$ & $3.94-5.48$ & $0.50-0.98$ & $3.05-4.53$ & $0.40-0.76$ & $0.18-0.42$ \\
\hline $\mathrm{TI} \mathrm{p}<0,001$ & $3.65-5.77$ & $0.41-1.07$ & $2.77-4.81$ & $0.34-0.82$ & $0.14-0.46$ \\
\hline \multicolumn{7}{|c|}{ Sick animals, $\mathrm{n}=24$} \\
\hline $\mathrm{M} \pm \mathrm{m}$ & $8.84 \pm 0.61^{\text {ooo }}$ & $3.96 \pm 0.65^{\text {ooo }}$ & $2.59 \pm 0.43$ & $4.44 \pm 0.62^{\text {ooo }}$ & $1.82 \pm 0.3^{\mathrm{oo}}$ \\
\hline $\mathrm{Lim}$ & $4.76-17.51$ & $0.78-14.15$ & $0.23-6.59$ & $0.38-10.79$ & $0.36-6.49$ \\
\hline $\mathrm{TI} \mathrm{p}<0,05$ & $7.59-10.09$ & $2.62-5.3$ & $1.71-3.46$ & $3.17-5.71$ & $1.20-2.43$ \\
\hline $\mathrm{TI} \mathrm{p}<0,01$ & $7.14-10.54$ & $2.14-5.78$ & $1.4-3.77$ & $2.71-6.17$ & $0.98-2.65$ \\
\hline $\mathrm{TI} \mathrm{p}<0,001$ & $6.67-11.11$ & $1.52-6.4$ & $0.99-4.18$ & $2.13-6.75$ & $0.7-2.94$ \\
\hline
\end{tabular}

Notes: CI in this table and others in the text:

$*$ - the difference between before and after treatment is significant for $p<0.05$;

$* *$ - for $p<0.01 ; * * *-$ for $p<0.001$. In this table and others in the text: ${ }^{\circ}-$ the difference between clinically healthy animals and before treatment is significant for $p<0.05$; ${ }^{\text {oo }}-$ for $p<0.01$; ${ }^{\text {ooo }}-$ for $p<0.001$

According to Table 2 for pancreatitis in the serum of total protein in $100 \%$ of dogs did not differ from those in clinically healthy individuals. The content of total bilirubin before treatment was 2.0 times higher than in control animals, which indicates the presence of functional liver failure and cholestasis syndrome. It is possible that in the acute course of pancreatitis due to the inflammatory process, which partially affects the liver (this correlates with the results of ultrasound in $75 \%$ of animals), edema occurs, which leads to bilirubin retention in the biliary tract and increased total bilirubin in serum of sick animals [209]. Concentrations of urea and creatinine only in some sick dogs exceeded the limits of the control group, but the average values and the corresponding confidence intervals probably did not differ from healthy animals. In the acute course of pancreatitis, hyperenzymemia was observed: ALT activity exceeded the index in the control group by 3.3, and AST increased, compared with the group of clinically healthy animals, 2.8 times. The increase in the simultaneous activity of ALT and AST indicates the development of cytolytic syndrome in the parenchyma of the pancreas and liver, as well as possible violations of the structure of the myocardium due to intoxication of patients with pancreatitis [17]. 
Table 2

The level of biochemical parameters of the serum of dogs with pancreatitis

\begin{tabular}{|c|c|c|c|c|c|c|c|}
\hline Indicator & ALAT, od/1 & $\mathrm{AST}, \mathrm{od} / \mathrm{l}$ & $\begin{array}{l}\text { Creatinine } \\
\mu \mathrm{mol} / 1\end{array}$ & Urea mmol/l & $\begin{array}{c}\text { Total bilirubin } \\
\mu \mathrm{mol} / 1\end{array}$ & $\begin{array}{l}\text { Total pro- } \\
\text { tein, } \\
\mathrm{g} / \mathrm{l}\end{array}$ & $\begin{array}{c}\alpha \text {-amylase } \\
\mathrm{g} /(\mathrm{h} \times \mathrm{l})\end{array}$ \\
\hline \multicolumn{8}{|c|}{ Clinically healthy animals, $n=15$} \\
\hline $\mathrm{M}$ & 32.6 & 29.4 & 91.4 & 6.2 & 5.7 & 65.2 & 80.6 \\
\hline $\mathrm{m}$ & 6.05 & 4.92 & 11.56 & 0.75 & 1.16 & 2.64 & 4.86 \\
\hline Lim & $7.5-67.0$ & $9.2-59.0$ & $44.5-140.1$ & $3.0-9.3$ & $0.9-10.9$ & $47.8-79.7$ & $56.1-109.2$ \\
\hline TI $\mathrm{p}<0,05$ & $19.8-45.5$ & $18.9-39.8$ & $66.8-116.0$ & $4.6-7.8$ & $3.2-8.2$ & $59.9-70.4$ & $70.2-90.9$ \\
\hline TI $p<0,01$ & $14.8-50.5$ & $14.8-43.8$ & $57.3-125.4$ & $4.0-8.4$ & $2.2-9.1$ & $57.9-72.4$ & $66.2-94.9$ \\
\hline TI $\mathrm{p}<0,001$ & $8.0-57.3$ & $9.3-49.4$ & $44.3-138.4$ & $3.1-9.2$ & $0.9-0.4$ & $55.1-75.2$ & $60.8-100.4$ \\
\hline \multicolumn{8}{|c|}{ Sick animals, $n=24$} \\
\hline $\mathrm{M}$ & $107.4^{000}$ & $82.0^{\circ 0}$ & 89.5 & 6.8 & $11.2^{\circ}$ & 67.9 & $228.3^{000}$ \\
\hline $\mathrm{m}$ & 13.34 & 10.67 & 8.08 & 0.40 & 0.90 & 2.09 & 17.1 \\
\hline Lim & $13.3-233.5$ & $10.0-173.4$ & $25.0-220.0$ & $3.3-10.7$ & $4.5-18.5$ & $49.8-89.1$ & $106.0-450.0$ \\
\hline TI $p<0,05$ & $79.9-134.9$ & $60.0-100.0$ & $72.8-106.2$ & $6.0-7.6$ & $9.4-13.1$ & $63.5-72.2$ & $193.0-263.6$ \\
\hline TI $p<0,01$ & $70.1-144.1$ & $52.2-111.8$ & $66.9-112.1$ & $5.7-7.9$ & $8.7-13.8$ & $62.0-73.7$ & $180.5-276.1$ \\
\hline TI $p<0,001$ & $57.4-157.4$ & $42.0-122.0$ & $59.2-119.8$ & $5.3-8.3$ & $7.9-14.6$ & $60.0-75.7$ & $164.2-292.4$ \\
\hline
\end{tabular}

The activity of $\alpha$-amylase $(228.3 \pm 17.1 \mathrm{~g} /(\mathrm{h} \times \mathrm{l}))$ increased with the highest probability $(\mathrm{p}<0.001)$, which may be due to inflammation of the pancreas and small intestine, as well as renal dysfunction. According to literature, a multiple increase in the activity of this enzyme indicates the development of pancreatitis [18]. Thus, in the acute course of pancreatitis before treatment there was no increase in total protein, urea and creatinine. Hyperbilirubinemia was detected in $54.2 \%$ of animals, as well as hyperfermentemia due to ALT (66.7 \%), AST (62.5\%) and $\alpha$-amylase $(95.8 \%)$.

\section{Discussion}

The lack of comprehensive data on the indicators of lipid metabolism in normal and various forms of pathology in dogs necessitates a comprehensive study of lipid metabolism, which is an important point in the diagnosis of these disorders. The difficulty of determining reliable indicators of the level of lipids and lipoproteins, most likely, depends on the different sensitivity of the methods, the diversity of experimental groups of animals, and their physiological state during the research, different environmental conditions and so on. Therefore, it was important to first determine the value of lipid metabolism in the serum of dogs without visible symptoms of pathology to create a control group of animals. Therefore, from the general sample of animals 15 (German Shepherd and outbred breeds) males and females were selected, 10 and 5 heads, respectively, at the age of 3-7 years, of approximately the same body weight without visible signs of pathology, which were kept in a diet close to the composition. outside the reference norms indicators of blood morphology, urine and biochemical analytes (total protein, albumin, ALT, AST, alpha-amylase, glucose, urea, creatinine, total and conjugated bilirubin). In the serum of animals of this group, in addition to these biochemical tests, determined the content of triacylglycerols, total cholesterol, as well as cholesterol of very low lipoproteins - VLDL, low - LDL and high density - HDL.

It was found that the content of total cholesterol in the serum of healthy dogs ranges from 2.99 to $6.86 \mathrm{mmol} / \mathrm{l}$ and averages $4.71 \pm 0.26 \mathrm{mmol} / \mathrm{l}$, i.e. does not differ significantly from the data given in other literature sources [17-19]. HDL cholesterol accounted for $80.5 \%$ of total cholesterol, i.e. most of it, which is typical for dogs as an animal species. According to the above-mentioned sources of literature, this fraction is quantitatively abundant in the serum of dogs. Dogs do not show the activity of the enzyme responsible for the transfer of cholesterol between different types of lipoproteins, which is essential in the so-called reverse transport of cholesterol with the participation of HDL, which takes place in the human body. This explains, at least in part, the uniqueness of dogs due to cholesterol metabolism. In human medicine, HDL is called antiatherogenic lipoproteins because they prevent the development of atherosclerosis by transferring cholesterol from tissues and blood vessels to the liver. It is believed that in healthy dogs, high levels of this fraction of lipoproteins contribute to the fact that these animals very rarely suffer from atherosclerosis [4].

The content of LDL cholesterol in the serum of animals of the experimental group was 6.5 times lower than the content of HDL cholesterol, and it accounts for $12.3 \%$ of the total. The concentration of VLDL cholesterol - lipoproteins containing a large amount of triacylglycerols, was $6.4 \%$ of the total content. The level of TG in the serum of clinically healthy dogs ranged from 0.21 to $1.32 \mathrm{mmol} / \mathrm{l}$ and averaged $0.74 \pm 0.08 \mathrm{mmol} / 1$.

We compared the data we obtained with the data of I. C. Jeusette [18]. It was found that the serum cholesterol content of the dogs we studied did not differ significantly from the results presented in this publication. The concentration of LDL cholesterol in our work was 3 times higher, which may be due to different housing conditions, type of animal nutrition, research methods, climatic and other factors. However, the cholesterol content of HDL, LDL and triacylglycerols did not differ significantly from the results of both sources.

Thus, our composition of the lipid profile of dogs coincides with the literature, which allowed us to use the results as controls for further studies of diseases that are accompanied by disorders of lipid and lipoprotein metabolism in dogs [17]. The values of traditional biochem- 
ical tests established in the course of work, which were determined in the serum of clinically healthy dogs, were within the relevant reference standards and did not differ significantly from the relevant limits. Therefore, all these indicators were used as controls (along with lipid metabolism) for further research.

We also examined 24 individuals with clinical signs of acute pancreatitis: increasing weakness, apathy, vomiting, foul-smelling diarrhea, fever; sometimes noted anemia, jaundice, ascites and other signs of exocrine insufficiency syndrome.

Examination of erythrocyte count and hemoglobin content in dogs with acute pancreatitis revealed a decrease in mean erythrocytopoiesis (erythrocytes by $33.3 \%$, hemoglobin $-24.0 \%$ ) indicates the development of anemia due to endogenous intoxication, which led to a decrease in physical formation and reduction of formation. This explains the symptom of pale mucous membranes, which was observed in $91.7 \%$ of sick dogs. The number of leukocytes probably did not differ from similar indicators in the group of clinically healthy animals. However, the proportion of rod-shaped neutrophils increased by $10.2 \%$, indicating the presence of an acute inflammatory process [207]. The proportion of lymphocytes in patients with pancreatitis in dogs was reduced by $11.5 \%$, which is an indicator of depletion of the immune system.

Biochemical study of blood serum is quite informative for pancreatitis [3]. However, most tests reflect not only the functional state of the pancreas, but also allow to assess the metabolic state of the sick animal as a whole, although some of the indicators (total protein, calcium, glucose, urea, creatinine, uric acid and thymol test) in the studied animals, according to Yu. M. Stork, do not change at all [1].

According to the results of research done by V. M. Lifshitz and V. I. Sidelnikov, the activity of enzymes in the serum outside the exacerbation of chronic pancreatitis is within normal limits [9]. A group of American scientists [6] conducted a study that determined the activity of alphaamylase and pancreatic lipase in the serum of healthy dogs (from 250 to 1500 and from 0 to $50 \mathrm{U} / \mathrm{l}$, respectively). The maximum limits of these tests for pancreatitis ranged: the activity of alpha-amylase from 4500 to 14000 units of Caraway, and pancreatic lipase - 325-810 U/l. As pancreatic tissue was further destroyed, enzyme activity increased rapidly, but alpha-amylase returned to normal earlier than pancreatic lipase. According to I. P. Kondrakhin [20] test for alpha-amylase activity is most sensitive in acute pancreatitis and exacerbation of chronic, and serum lipase activity test for chronic pancreatitis. According to Kaneko J. [3], the activity of alpha-amylase in acute pancreatitis in dogs, as in humans, increases in the first 12-48 hours, but normalization occurs only on day $8-14$. However, it should be borne in mind that the activity of serum alpha-amylase does not always correspond to the form of pancreatitis. Alphaamylase activity may be increased in diseases that have similar clinical symptoms to acute pancreatitis - peritonitis, gastritis, gastric ulcer and acute intestinal obstruction. The increase in the activity of this enzyme can be caused by many reasons, namely inflammation of the pancreas and small intestine and impaired renal function. According to the medical literature, an increase in the activity of this enzyme in 45 times indicates pancreatitis, but amylase-creatinine clear- ance should be calculated to confirm the diagnosis. A decrease rather than an increase in blood $\alpha$-amylase activity is an indicator of a decrease in the exocrine function of the gland, which is inherent in aging and the process of replacing its parenchyma with connective tissue [1].

According to our data, in the acute course of pancreatitis it was found that hyperlipidemia developed due to an increase in total cholesterol by 1.9 times - in $79.2 \%$ and TG in 5.4 times - in $91.7 \%$ of sick animals compared to clinically healthy dogs. After treatment, cholesterol levels returned to normal and TG levels decreased, but remained 2.5 times greater than in clinically healthy animals. The most significant quantitative changes were inherent in the LDL fraction - in $75 \%$ of animals (increase in cholesterol levels of this fraction by 7.7 times). This indicates severe damage to both the pancreas and liver, in which there is a partial synthesis of low-density lipoproteins. After treatment, the rate decreased compared to baseline by 3.1 times, but still remained higher than in animals of the control group. Similar data were obtained for human pancreatitis [4]. The same applies to the dynamics of the cholesterol content of the VLDL fraction, when the rate was increased 6.0 times in $91.7 \%$ of dogs, and after treatment decreased by 2.5 times, still remaining higher than in animals of the control group.

Thus, in the acute course of pancreatitis (or exacerbation of chronic) indicators of lipid and lipoprotein metabolism are characterized by significant changes: increasing levels of total cholesterol, triacylglycerols, LDL cholesterol and VLDL, with the exception of blood cholesterol in which the concentration of HDL is reduced.

Treatment helped to normalize total cholesterol, but the concentration of triacylglycerols remained high. The cholesterol content of LDL and VLDL decreased, but did not reach the values of the control group. Treatment also did not help to normalize HDL cholesterol levels, which remained significantly lower than in clinically healthy animals. The pathogenesis of hyperlipidemia in canine pancreatitis is shown in Fig. 1.

As for changes in traditional biochemical tests, the serum of dogs in acute pancreatitis (or exacerbation of chronic) in the content of total protein before and after treatment in $100 \%$ of animals did not differ from those in the control group.

The content of total bilirubin in $45.8 \%$ of dogs increased 2.0 times, indicating a violation of its detoxification, excretion, congestion in the biliary tract, and after treatment in all animals the figure reached the confidence interval calculated for clinically healthy animals [17]. The concentration of urea and creatinine in pancreatitis in most animals was also within the relevant CI before and after treatment, indicating the absence of significant renal impairment. Hyperenzymemia was observed in sick dogs: ALT activity increased 3.3 times in $66.7 \%$ of individuals, and AST -2.8 times in $62.5 \%$. After a course of treatment, the activity of enzymes decreased significantly.

In the most acute course of pancreatitis, the activity of $\alpha$-amylase increased in $95.8 \%$ of animals $(228.3 \pm 17.1$ $\mathrm{g} /(\mathrm{h} * \mathrm{l})$, and after treatment the indicator decreased by 1.9 times ( $\mathrm{p}<0.001$ ), however, in most dogs remained above the upper limit of CI for animals in the control group.

Thus, it was found that the most informative tests for exacerbation of pancreatitis were $\alpha$-amylase $(95.8 \%)$, TG 
and cholesterol VLDL (91.7 \%), total cholesterol and LDL (79.2 and 75.0\%, respectively). ALT and AST (66.7 and $62.5 \%$, respectively), as well as HDL cholesterol and total bilirubin $(54.2 \%)$, were less informative in the acute course of canine pancreatitis.

The informativeness of total protein, urea and creatinine was low, as deviations from the control group were observed in less than $50 \%$ of animals with pancreatitis.

When determining the informativeness of the above tests to assess the effectiveness of treatment of pancreatitis in dogs, we took into account the percentage of animals in which the level or activity of the indicator remained outside the limits of the control group, i.e. not normalized.

The control group in more animals included tests such as total cholesterol (87.5\%), total bilirubin (79.2\%), ALT and AST (75.0 and $70.8 \%)$.

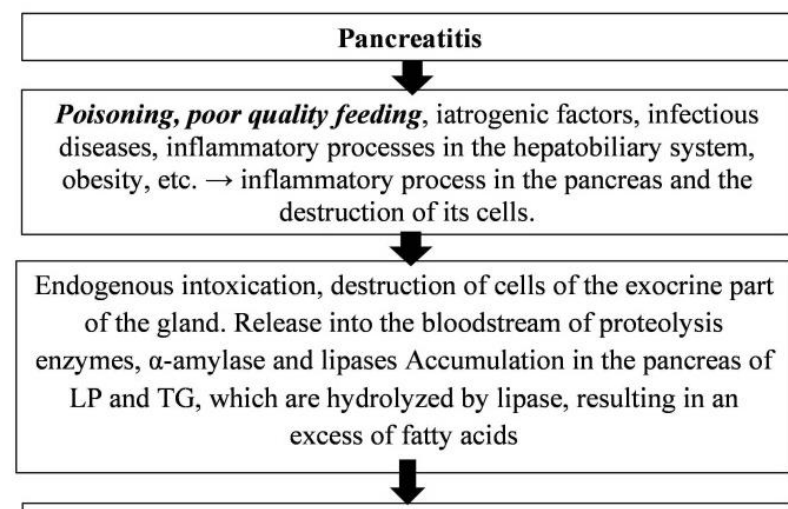

Toxic effects on acinar cells and epithelium of the gland of fatty acids, chylomicrons, VLDL, microcirculation disorders, edema, stagnation, the threat of autolysis of the pancreas.

\begin{tabular}{|c|}
\hline $\begin{array}{c}\text { Acute,and under the constant action of pathogenic factors - } \\
\text { chronic inflammation. Disorders of microcirculation, edema, foci } \\
\text { of necrosis and autolysis of the parenchyma of the gland. } \\
\text { formation of connective tissue cells (in the case of chronicity of } \\
\text { the process). }\end{array}$ \\
\hline $\begin{array}{c}\text { endogenous intoxication, cytolysis of hepatocytes, } \\
\text { hepatocellular insufficiency, mesenchymal-inflammatory } \\
\text { syndrome }\end{array}$ \\
\hline Indigestion, changes in the pH of the chyme, dysbacteriosis \\
\hline $\begin{array}{c}\text { Inflammatory process in the biliary tract, cholestasis, } \\
\text { accumulation of LDL, which include pathological } \\
\text { lipoprotein } \boldsymbol{X}(\boldsymbol{L P X})\end{array}$ \\
\hline HYPERLIPIDEMIA \\
\hline
\end{tabular}

Fig. 1. Pathogenesis of hyperlipidemia in canine pancreatitis

Informative indicators for the diagnosis of acute pancreatitis, such as $\alpha$-amylase activity, TG and cholesterol content of all fractions of the lipid profile, during treatment were above the control group in a significant number of dogs. Thus, the content of TG and LDL cholesterol remained elevated in $41.7 \%$ of animals, VLDL in $45.8 \%$, HDL, on the contrary, was reduced in the same number of dogs $(45.8 \%)$. The largest share was in patients with pancreatitis dogs, in which after treatment remained above the control group $\alpha$-amylase activity
$(62.5 \%)$. During the treatment there were also changes in the tests, which were uninformative for the diagnosis of pancreatitis (total protein, urea, and creatinine). The total protein content was higher than the control group in $8.3 \%$ of dogs, urea exceeded the upper and lower limits in $25 \%$, and creatinine concentration was increased in $12.5 \%$ of animals. It is possible that these animals had a deterioration in the functional state of the kidneys.

Thus, in the acute course of pancreatitis in dogs, such biochemical parameters as the level of total protein, urea, and creatinine do not change significantly, the concentration of bilirubin increases, there is hyperenzymemia of ALT and AST. However, the biggest changes in canine pancreatitis are inherent in the activity of $\alpha$ amylase and the metabolism of lipids and lipoproteins in the serum: the concentration of total cholesterol, TG, LDL cholesterol and especially LDL cholesterol. HDL cholesterol, in contrast, in the acute course of pancreatitis was lower than in clinically healthy dogs.

Therapeutic measures help to reduce the degree of hyperenzymemia, but the activity of $\alpha$-amylase in many animals is not normalized. After treatment, in addition, the content of triacylglycerols, LDL cholesterol and VLDL remains above normal. Most dogs have normalized serum total cholesterol, but HDL cholesterol levels in many animals remain low compared to clinically healthy animals, despite treatment. These results indicate that the treatment did not fully ensure the normalization of metabolic processes, in particular lipid metabolism, in the acute course of pancreatitis in some animals. In such cases, the scheme and regulations of treatment require appropriate correction from the doctor.

Study limitations. The obtained results cannot fully characterize all lipid features of a pancreatitis in animals.

Prospects for further research. In the future, we plan to conduct studies of various aspects metabolizm of lipid in different types of animals.

\section{Conclusions}

1. In work on the basis of clinical symptoms, ultrasound, general clinical analysis of blood, results of complex laboratory research of blood serum with inclusion of indicators of lipid metabolism - triacylglycerols, total cholesterol, cholesterol of very low lipoproteins (VLDL), low (LDL) and high (HDL) density was substantiated pathogenetic role of lipid metabolism disorders in the development and course of pancreatitis

2. The high informativeness of these indicators for the diagnosis and evaluation of the effectiveness of treatment of pancreatitis along with traditional diagnostic tests (the level of total protein, total bilirubin, total cholesterol, urea, creatinine and the activity of ALT, AST and $\alpha$-amylase).

3. The serum lipidogram of dogs without clinical symptoms of pathology does not differ in composition from the results obtained by other researchers, except for higher levels of VLDL cholesterol. The content of total cholesterol in the serum of dogs is $4.71 \pm 0.26 \mathrm{mmol} / 1$, triacylglycerols $-0.74 \pm 0.08 \mathrm{mmol} / \mathrm{l}$, VLDL cholesterol $0.30 \pm 0.04$, HDL cholesterol $-3.79 \pm 0.25$, LDL cholesterol $-0.58 \pm 0.06 \mathrm{mmol} / \mathrm{l}$. The share of HDL cholesterol is $80.5 \%$ of the concentration of total cholesterol, LDL cholesterol - 12.3, LDL cholesterol $-6.4 \%$. 
4. In dogs with serum pancreatitis, the concentration of total cholesterol increases 1.9 times, triacylglycerols -5.4 times, LPDN cholesterol -6.0 times and LDL cholesterol -7.7 times. The content of HDL cholesterol, in contrast, in the acute course of pancreatitis is 1.5 times lower than in clinically healthy dogs. Treatment helps to reduce the degree of hyperenzymemia by ALT and AST, but $\alpha$-amylase activity is not normalized in some dogs. Above normal levels of triacylglycerols, LDL cholesterol and VLDL, and HDL cholesterol remain low, despite treatment.

\section{Conflict of interests}

The authors declare that they have no conflicts of interest.

\section{Financing}

The study was performed without financial support.

\section{References}

1. Busel, Yu. M. (2011). Pankreatyt u sobak (patohenez, diahnostyka i likuvannia). Bila Tserkva, 20.

2. Lokes, P. I., Kibkalo, D. V., Liakhovych, K. V. (2009). Diahnostychna znachymist biokhimichnykh pokaznykiv syrovatky krovi sobak za hepatorenalnoho syndromu. Visnyk Poltavskoi derzhavnoi ahrarnoi akademii, 3, 87-93.

3. Kaneko, J., Harvey, J., Bruss, M. (1997). Clinical Biochemistry of Domestic Animals. Academic Press, 932. doi: http://doi.org/10.1016/b978-0-12-396305-5.x5000-3

4. Boikiv, D. P., Bondarchuk, T. I., Ivankiv, O. L. et. al. (2007). Biokhimichni pokaznyky v normi i pry patolohii. Kyiv: Medytsyna, 320.

5. Tymoshenko, O. P., Zemlianskyi, A. O., Vyhovska, K. L., Kuzmina, Yu. V. (2013). Pokaznyky lipidohramy syrovatky krovi sobak bez klinichnykh oznak patolohii. Naukovyi visnyk Luhanskoho natsionalnoho ahrarnoho universytetu, 49, $136-140$.

6. Xenoulis, P. G., Steiner, J. M. (2010). Lipid metabolism and hyperlipidemia in dogs. The Veterinary Journal, 183 (1), 12 21. doi: http://doi.org/10.1016/j.tvj1.2008.10.011

7. Kirk, R., Bonagura, Dzh. D. (2005). Sovremennii kurs terapii Kirka. Moscow: Akvarium print, 1376.

8. Salupere, V. (1988). Klinicheskaia gastroenterologiia. Tallin: Valgus, 288.

9. Horalskyi, L. P., Tymoshenko, O. P., Borysevych, B. V. et. al.; Horalskyi, L. P. (Ed.) (2013). Pankreatyt sobak. Zhytomyr: «Polissia», 216

10. Nimand, Kh. G., Suter, P. F. (2004). Bolezni sobak. Moscow: Akvarium-print, 816.

11. Vasilevich, F. I., Golubeva, V. A., Danilov, E. P. et. al. (2001). Bolezni sobak. Moscow: Kolos, 472.

12. Batchelor, D. J., Noble, P.-J. M., Taylor, R. H., Cripps, P. J., German, A. J. (2007). Prognostic Factors in Canine Exocrine Pancreatic Insufficiency: Prolonged Survival is Likely if Clinical Remission is Achieved. Journal of Veterinary Internal Medicine, 21 (1), 54-60. doi: http://doi.org/10.1111/j.1939-1676.2007.tb02928.x

13. Hallay, J., Kovacs, G., Szarmari, K. et. al. (2001). Early jejunal nutrition and changes in the immunological parameters of patients with acute pancreatitis. Hepatogastroenterology, 48 (41), 1488-1492.

14. Sympson, D., Uéls, R. (2003). Bolezny pyshchevarytelnoy systemy sobak i koshek. Moscow: Akvaryum-LTD, 496.

15. Shalimov, O. O., Hrubnyk, V. V., Horovits, Dzh. (2000). Khronichnyi pankreatyt. Suchasni kontseptsii patohenezu, diahnostyky i likuvannia. Kyiv: Zdorovia, 256.

16. Rebrova, O. Iu. (2002). Statisticheskii analiz meditsinskikh dannykh. Primenenie paketa prikladnykh programm STATISTIKA. Moscow: Medi Sfera, 312.

17. Zemlianskyi, A. A., Lokes-Krupka, T. P., Kuzmina, Iu. V. (2014). Pokazateli lipidogrammy syvorotki krovi sobak i koshek bez klinicheskikh priznakov patologi. Mezhdunarodnii vestnik veterinari, 1, 52-56.

18. Osorio, J. H. (2009). The variability in the canine lipid profile values and its possible relationship with the measurement method used. Vet. zootec., 3 (1), 70-77.

19. Vlizlo, V. V., Fedoruk, R. S., Ratych, I. B. et. al.; Vlizlo, V. V. (Ed.) (2012). Laboratorni metody doslidzhen u biolohii, tvarynnytstvi ta veterynarnii medytsyni. Lviv: SPOLOM, 764.

20. Levchenko, V. I., Holovakha, V. I., Kondrakhin, I. P. et. al.; Levchenko, V. I. (Ed.) (2010). Metody laboratornoi klinichnoi diahnostyky khvorob tvaryn. Kyiv: Ahrarna osvita, 437.

Received date 19.08.2021

Accepted date 16.09.2021

Published date 30.09.2021

Andrii Zemlianskyi, PhD, Assistant, Department of Veterinary Medicine and Pharmacy, National University of Pharmacy, Pushkinska str., 53, Kharkiv, Ukraine, 61002

Olga Tymoshenko, Doctor of Biological Sciences, Professor, Department of Clinical Diagnostics and Clinical Biochemistry, Kharkiv State Zoological and Veterinary Academy, Akademichna str., 1, Malaya Danilovka, Kharkiv region, Ukraine, 62341

Andriy Zakhariev, PhD, Associate Professor, Department of Veterinary Medicine and Pharmacy, National University of Pharmacy, Pushkinska str., 53, Kharkiv, Ukraine, 61002

Yevheniia Vashchyk, Doctor of Veterinary Sciences, Associate Professor, Department of Veterinary Medicine and Pharmacy, National University of Pharmacy, Pushkinska str., 53, Kharkiv, Ukraine, 61002

Nataliia Seliukova, Doctor of Biological Sciences, Associate Professor, Department of Veterinary Medicine and Pharmacy, National University of Pharmacy, Pushkinska str., 53, Kharkiv, Ukraine, 61002

Roman Dotsenko, PhD, Senior Researcher, Associate Professor, Department of Veterinary Medicine and Pharmacy, National University of Pharmacy, Pushkinska str., 53, Kharkiv, Ukraine, 61002

*Corresponding author: Andrii Zemlianskyi,e-mail: totty.toy007@gmail.com 